Meta

Ušeničnik

Center za social-

no delo Ljubljana

Vič-Rudnik

\title{
PRIPRAVA \\ NA UPOKOJITEV
}

\section{Ali slovenska podjetja in bodoči upokojenci načrtujejo odhod $v$ pokoj?}

E ljenja je starost. Nekakšen mejnik, ki loči življenje zrele, aktivne osebe od starosti, pomeni upokojitev. O pomenu besede upokojitev nam precej pove že izvor besede, ki izhaja iz besede pokoj. Ta označuje stanje brez hrupa, vznemirjenja, stanje notranje ubranosti, urejenosti, brez napetosti. Posameznik naj bi si po napornem delovnem obdobju zaslužil mir. Vendar tudi mir ni vedno darilo, če ga ne znaš uživati. Nanj se je treba

Namen priprave
na upokojitev
je vecja samostoj-
nost, odločnost,
motivacija in
kreativnost
bodočith
upokojencev.
pripraviti.

$\mathrm{V}$ današnjem času živi posameznik po upokojitvi še 20 do 25 let, kar pomeni četrtino njegovega življenja. Upokojitev je lahko zanj sprememba, ki se ji ne zna prilagoditi. Vse delovno obdobje se je identificiral s svojim delom in vanj usmerjal večino svoje energije in želja, kar naenkrat pa se mora, če želi ali ne, umakniti. Življenje si je prisiljen na novo začrtati. Upokojitev vsak doživlja osebno, drugače od drugih. Zato mora družba poskrbeti za čim lažji prehod iz delovnega življenja v življenje po upokojitvi. Žal družba to svojo dolžnost prevečkrat zanemari, tako da prevlada »zakon močnejšega«, ki starejše, upokojene še bolj zaznamuje.

\section{PRIPRAVA NA UPOKOJITEV}

$\mathrm{Z}$ upokojitvijo se za večino ljudi konča osrednji del življenjske sestavljanke: poklicno življenje, ki se ga ne more enostavno nadomestiti $\mathrm{z}$ nečim drugim. Da postane življenje (sestavljanka) zopet celota, se morajo spremeniti tudi drugi sestavni deli. Upokojitev torej ni le konec plačanega dela, pomeni tudi, da se morajo prilagoditi na vseh življenjskih področjih.

Upokojitev posamezniku prinese mnogo sprememb, ki se jim mora čim bolj konstruktivno prilagoditi. Tako rekoč čez noč izgubi prijatelje iz delovnega okolja, družbeni položaj, ki si ga je ustvarjal v svojem poklicnem življenju, spremeni se njegovo finančno stanje in ima 10 ur več prostega časa na dan. Prilagoditev na novo nastalemu položaju zahteva veliko energije.

Izkušnja upokojitve je odvisna od mnogih dejavnikov. Woodruff in Birren (Ledbetter Hancock, 1990, str. 223) navajata štiri dejavnike, ki vplivajo na pozitivno doživljanje upokojitve:

- prostovoljna upokojitev;

- primeren dohodek in zadovoljivo zdravje, ki omogočata udobno življenje;

- zavest, da delo ni najpomembnejše v posameznikovem življenju;

- priprava in načrtovanje življenja po upokojitvi.

»Kritični dogodek « upokojitve se redko zgo- 
Atachley (Ledbetter Hancock, 1990, str. 223) razlikujeta pet faz upokojevanja:

1. pred upokojitvijo: oseba si skuša predstavljati upokojitev;

2. »medeni tedni«: čas, ko skuša uresničiti, izkusiti predstave o upokojitvi;

3. stabilnost: če je obdobje medenih tednov uspešno, sledi obdobje stabilnosti;

4. faza nenavdušenja: če upokojitev ni taka, kot pričakuje, po obdobju »medenih tednov« doživi razočaranje;

5. preusmeritev: razvije realen pogled na alternative in začne odkrivati nove interese.

di čez noč. Približevanje dneva upokojitve, samo upokojitev in čas po njej ljudje različno doživljajo.

Za nekatere je upokojitev kot rahlo drsenje $\mathrm{v}$ dolgo pričakovano obdobje življenja, drugi doživljajo ta korak kot skok v neznano. V novem življenjskem obdobju se težko znajdejo predvsem tisti, ki so smisel svojega življenja iskali in našli v delu ter so mu bili predani do zadnjega dne pred upokojitvijo.

Najboljša priprava na upokojitev združuje teorijo in prakso. To pomeni, da se o upokojitvi učimo, čutimo dolžnost, da bi bilo nekaj treba storiti in končno to tudi storimo. Pomemben korak naredimo, ko spoznamo, da je upokojitev pomembno obdobje v človekovem življenju. Posledica priprave na upokojitev je, da se človek oboroži s potrebnimi informacijami, oceni svoj resnični položaj, izmenjuje ideje in načrte $\mathrm{z}$ drugimi, je manj zaskrbljen ter se odloči, kaj bo počel v pokoju.

\section{PRIPRAVA NA UPOKOIITEV V SLOVENIJI - IZSLEDKI RAZISKAVE IZ LETA 1997}

V diplomski nalogi s temo Priprava na upokojitev sem se odločila opraviti tudi raziska- vo, katere namen je bil ugotoviti, ali pripravo na upokojitev sploh poznamo in, če jo, koliko je razširjena $v$ našem prostoru ali pa je sploh ne poznamo. $V$ zvezi s tem me je zanimalo tudi mnenje upokojencev ter podjetij in drugih organizacij oziroma to, kolikšno pomembnost ji pripisujejo, kako naj bi potekala, katere vsebinske sklope naj bi zajemala.

\section{Vrsta raziskave, merski instrumenti, vzorčenje}

Raziskavi sta bili izvedeni v avgustu in septembru 1997. Bili sta empirični in $\mathrm{v}$ obeh je bil merski instrument standardizirana anketa. Vprašalnik za kadrovsko službo je bil razdeljen na tri vsebinske sklope in je obsegal 17 vprašanj. Vprašanja v zadnjem sklopu vprašalnika so bila namenjena le podjetjem in organizacijam, ki izvajajo pripravo na upokojitev. Vprašalnik za upokojence je sestavljalo 22 vprašanj. Vprašanja so bila večinoma zaprtega tipa, le nekatera so bila odprtega. Anketiranci so lahko pri nekaterih vprašanjih

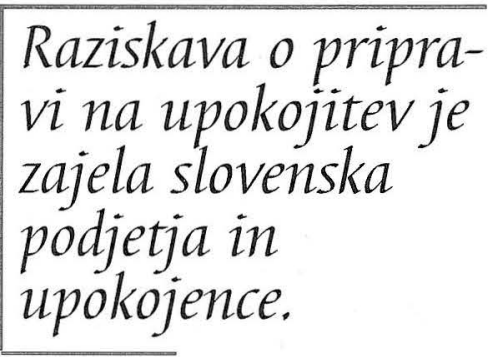
obkrožili več odgovorov. Pri nekaterih vprašanjih so izražali svoje mnenje glede na stopnjo potrebnosti v razponu od 1 do 5 , pri čemer sta pomenila: 1 - zelo potrebno in 5 - nepotrebno.

Prvo raziskavo sem izvedla $\mathrm{v}$ kadrovskih službah ${ }^{1}$ različnih slovenskih podjetij in v organizacijah. Podatke o podjetjih sem dobila v Gospodarskem vestniku (GV, 1997, str. 41-59), podatke o drugih organizacijah pa v programski verziji TIS 95. Izbrala sem enostavni slučajnostni vzorec in izžrebala 50 podjetij ter drugih organizacij. Da bi se izognila prevelikemu osipu, sem vsako od kadrovskih služb prej po telefonu prosila, ali lahko pošljem anketo. Po telefonu mi je uspelo dobiti le 36 kadrovikov in vsi so privolili v sodelovanje. Izpolnjen vprašalnik mi je vrni- 
lo 21 podjetij in drugih organizacij, kar pomeni, da je bil osip 42-odstoten. 48 odstotkov organizacij, zajetih $\mathrm{v}$ raziskavo, pomeni javni sektor, 52 odstotkov pa zasebni sektor.

Drugo raziskavo sem opravila med upokojenci. V programski verziji TIS 95 sem poiskala društva upokojencev v Sloveniji in izmed njih naključno izbrala 15 društev. Tudi njih sem prej prosila za sodelovanje in pomoč pri razdelitvi anketnih listov. Prav tako kot v kadrovskih službah so bili tudi v društvih upokojencev pripravljeni sprejeti vprašalnike in jih razdeliti. Glede na število upokojencev sem se odločila, koliko vprašalnikov bom poslala posameznemu društvu. Razposlala sem 121 vprašalnikov, izpolnili pa so jih 90 , kar pomeni 74-odstoten odziv. $\mathrm{V}$ raziskavo sem želela vključiti upokojence, ki so upokojeni največ pet let, vendar se je kasneje izkazalo, da so vprašalnike izpolnjevali tudi upokojenci $\mathrm{z}$ daljšim upokojenskim stažem. Povprečna upokojenska doba respondentov je bila 5,4 leta. $\mathrm{Na}$ anketo se je odzvalo največ upokojencev, ki so upokojeni štiri do šest let. 64 odstotkov respondentov je upokojenih največ pet let, 36 odstotkov pa dlje kot pet let.

\section{Rezultati in razprava}

Rezultate raziskave lahko povzamemo za posamezno populacijo takole:

\section{Kadrovska služba}

- Pri vprašanju, kako v organizaciji ali podjetju skrbijo za dobro počutje starejših zaposlenih, so lahko respondenti obkrožili več odgovorov. Podjetja in druge organizacije posvečajo najmanj pozornosti svetovanju in izobraževanju. Svetovanje imajo v 24 in izobraževanje v 29 odstotkih podjetij ter organizacij. Na drugi strani pa 57 odstotkov podjetij in drugih organizacij omogoča starejšim zaposlenim prilagoditev delovnega mesta. Najvišji je delež tistih (71 odstotkov), ki ne izključujejo možnosti napredovanja. Povprečno število dejavnosti, s kate- rimi podjetja in druge organizacije skrbijo za starejše zaposlene, je 1,8 .

- Podjetja in druge organizacije različno skrbijo tudi za že upokojene delavce. Najpogostejša oblika dejavnosti v zvezi s tem je organiziranje upokojenskih srečanj. Srečanja organizirajo kar v 76 odstotkih podjetij in drugih organizacij. Z 48 odstotki sledi pošiljanje voščilnic ob praznikih in jubilejih, 43 odstotkov podjetij pa upokojencem omogoča podobne ugodnosti kot zaposlenim, na primer možnost letovanja $\mathrm{v}$ pred- ali posezoni po sindikalni ceni, darilni boni ali popust pri nakupu izdelkov, ki jih izdeluje podjetje, 33 odstotkov zanje organizira tudi izlete, 10 odstotkov pa jim pošilja interno glasilo. V dveh podjetjih imajo klub upokojencev, katerega dejavnost finančno podpirata, neko podjetje pa svoje upokojence ob novem letu obdari. Povprečno število dejavnosti, s katerimi podjetja in druge organizacije skrbijo za upokojence, je 2,3.

- Večja podjetja pripisujejo pripravi na upokojitev več pomena. Vzrok, da se večjim podjetjem zdi priprava na upokojitev po-

Podjetja in druge organizacije ponavadi bolje skrbijo za upokojence kot za starejše zaposlene. Ena od možnih razlag je lahko, da podjetja ne obravnavajo starejših zaposlenih nič drugače in so le del »množice « brez posebnih potreb, upokojenci pa so posebna, ločena skupina, ki se lažje prepozna in se zato zanjo tudi lažje poskrbi. Prav tako je skrb, ki jo namenjajo upokojencem, bolj enkratne in skupinske narave (na primer srečanje, pošiljanje voščilnic) in podjetju oziroma organizaciji ne vzame toliko časa. Skrb za starejše zaposlene je $v$ nasprotju $\mathrm{s}$ tem individualna (prilagoditev delovnega mesta, izobraževanje) in, če se izvaja dosledno in kakovostno, zahteva več časa ter denarja. S petodstotnim tveganjem lahko tudi trdimo, da večja podjetja bolje skrbijo za upokojence. 
membnejša, je lahko $v$ tem, da imajo več upokojencev in upokojitev na leto, zato se jim zdi problematika upokojevanja pomembnejša.

- Podjetja in druge organizacije večinoma menijo, da je priprava na upokojitev potrebna. Pri tem pomenita 1 - zelo potrebna in 5 - ni potrebna. Kar 43 odstotkov anketirancev je odgovorilo, da je priprava na upokojitev potrebna, 38 odstotkov je zavzelo srednje stališče, 19 odstotkov pa jih meni, da priprava na upokojitev ni toliko potrebna. Povprečna ocena stopnje potrebnosti priprave na upokojitev je 2,8 . Ta podatek je spodbuden in kaže na to, da zaposleni v kadrovskih službah spoznavajo pomen in potrebnost priprave na upokojitev.

- Največ, 57 odstotkov, anketirancev meni, naj bi se priprava na upokojitev začela izvajati vsaj eno leto pred upokojitvijo, 14 odstotkov jih meni, da bi se morala začeti izvajati vsaj tri leta pred upokojitvijo, 10 odstotkov med postopkom upokojevanja, le 5 odstotkov pa meni, da bi se morala začeti vsaj pet let pred upokojitvijo. Rezultati so zanimivi predvsem zato, ker se je večina opredelila ravno v nasprotju s tem, kar priporočajo nova spoznanja o pripravi na upokojitev, v skladu s katerimi naj bi se posameznik na upokojitev in starost pripravljal vrsto let pred upokojitvijo, saj se v zadnjem letu ali dveh ne da nadomestiti zamujenega in temeljito pripraviti na upokojitev ter starost.

- Pri vprašanju, koliko časa naj bi trajala priprava na upokojitev, kažejo rezultati dve prevladujoči skupini mnenj. Nekateri, 33 odstotkov, menijo, da za pripravo na upokojitev zadostujeta eno ali dva srečanja. Prav tako 33 odstotkov jih je mnenja, da bi morala priprava na upokojitev obsegati pet in več srečanj, 19 odstotkov anketirancev pa sestavlja nekakšno vmesno skupino, ki meni, da naj bi priprava na upokojitev zajela tri do štiri srečanja.

\section{Graf 1: Kaj naj obsega program priprave na upokojitev?}

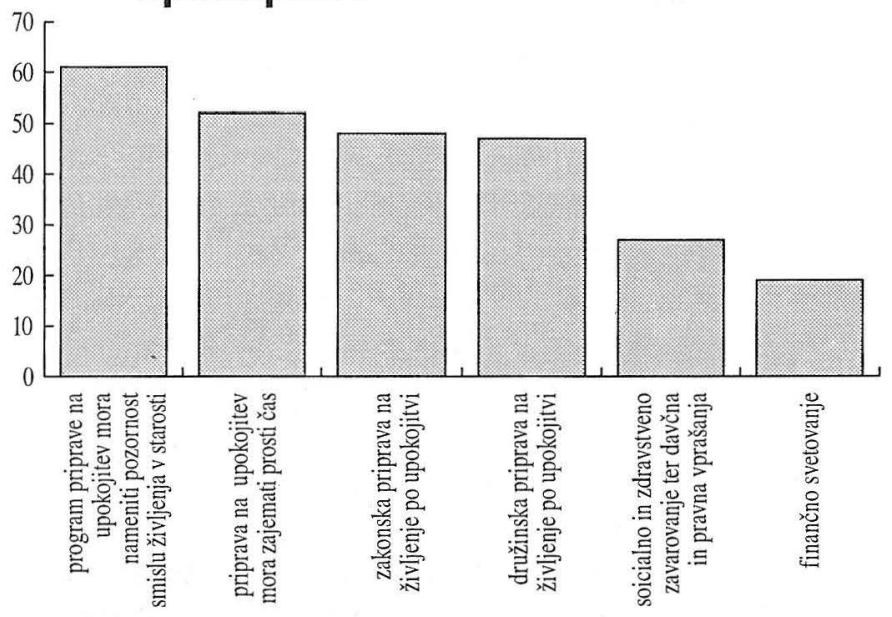

- Večina (62 odstotkov) meni, da naj bi bila priprava na upokojitev organizirana individualno, 42 odstotkov jih zagovarja skupinsko pripravo na upokojitev. Manjšini, 19 odstotkom, pa bolj ustreza individualen način priprave, s partnerjem.

- Anketiranci dajejo velik pomen smislu življenja v starosti: kar 61 odstotkov jih meni, da bi moral biti program priprave na upokojitev osredotočen na smisel življenja v starosti, 52 odstotkov anketirancev se je odločilo, da bi priprava na upokojitev morala zajemati tematiko prostega časa, tesno, z 48 in 47 odstotki, ji sledita zdravje in zakonska oziroma družinska priprava na življenje po upokojitvi. Na petem mestu, 27 odstotkov, so področje socialnega in zdravstvenega zavarovanja ter davčna in pravna vprašanja, najmanj anketirancev, 19 odstotkov, pa bi v program priprave na
Ceprav večina slovenskih podjetij priznava nujnost priprave na upokojitev, jo izvajajo le $v$ vecjith podjetjith. upokojitev vključilo finančno svetovanje.

- Pripravo na upokojitev izvajata med podjetji, vključenimi v raziskavo, le dve. Prvo podjetje ima 350 zaposlenih, drugo pa 800 . Pri obeh podjetjih je priprava na upokojitev 
organizirana individualno. $\mathrm{V}$ obeh podjetjih pri pripravi na upokojitev posvečajo pozornost predvsem socialnemu in zdravstvenemu zavarovanju ter davčnim in pravnim vprašanjem. $\mathrm{V}$ prvem podjetju se $\mathrm{z}$ bodočim upokojencem pogovarjajo tudi o prostem času, vendar se jim zdijo prav tako pomembne teme tudi finančno svetovanje, smisel življenja v starosti in zakonska oziroma družinska priprava na upokojitev, ki pa je žal njihov program ne vključuje. V drugem podjetju zaposlenemu pred upokojitvijo svetujejo v zvezi s finančnimi zadevami. V prvem podjetju začnejo bodoče upokojence pripravljati na upokojitev praviloma eno leto pred upokojitvijo, čeprav menijo, da bi se morala priprava na upokojitev začeti izvajati vsaj tri leta prej. Priprava na upokojitev obsega pri njih ponavadi tri do štiri srečanja, dolžina je odvisna od posameznika. V drugem podjetju začnejo starejše zaposlene pripravljati na upokojitev vsaj pet let pred upokojitvijo, vendar menijo, da bi bilo dovolj zgodaj tudi tri leta pred upokojitvijo, priprava na upokojitev pa traja 12 ur.

\section{Graf 2: Kako upokojenci preživljajo svoj prosti čas?}

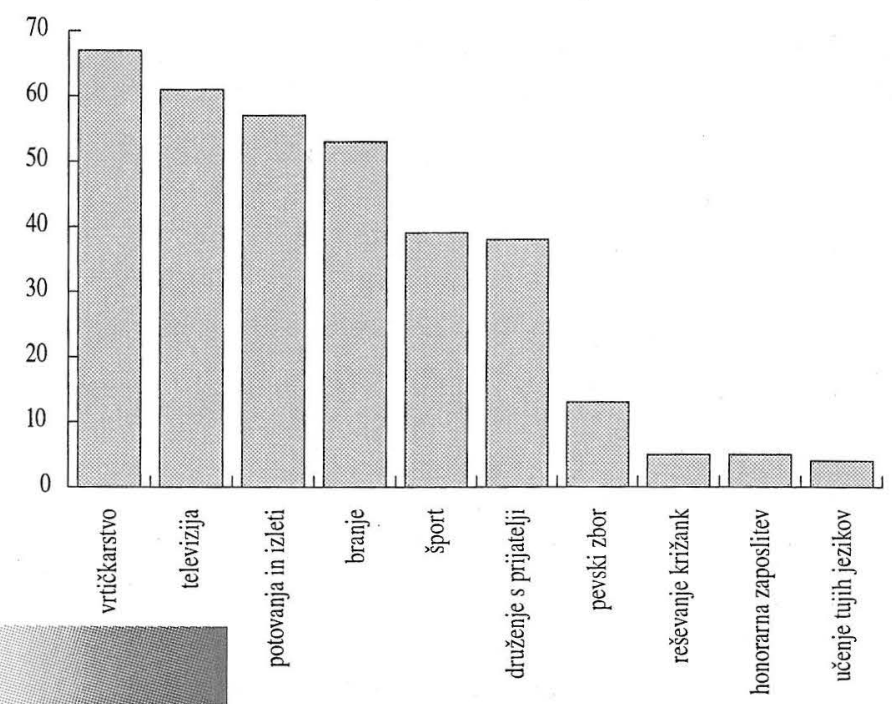

\section{Upokojenci}

- Večina, to je 51 odstotkov anketirancev, se je na življenje po upokojitvi delno pripravljala. Kar 38 odstotkov jih je odgovorilo, da življenja po upokojitvi niso načrtovali in da se nanj niso pripravljali. O tem, kako bodo živeli po upokojitvi, je zelo razmišljalo 9 odstotkov anketirancev. To pomeni, da se jih je 60 odstotkov nekako pripravljalo in načrtovalo življenje po upokojitvi.

- 22 odstotkov anketirancev je imelo v podjetju ali drugi organizaciji organizirano pripravo na upokojitev, 30 odstotkov jih meni, da so se jim na delovnem mestu ob upokojitvi dovolj posvetili, kar 67 odstotkov pa, da so se jim posvetili premalo oziroma sploh ne.

- 39 odstotkov anketirancev se je o pripravi na upokojitev pogovarjalo predvsem s partnerjem, 33 odstotkov s sodelavci, 29 odstotkov pa s kadrovikom, prijatelji, zdravnikom in svetovalnim delavcem. Anketiranci so se o upokojitvi pogovarjali tudi z otroki in v krogu družine.

- Največ, 37 odstotkov, jih meni, da je priprava na upokojitev zelo pomembna, $v$ nasprotju z njimi pa jih 14 odstotkov meni, da sploh ni potrebna, 24 odstotkov jih je zavzelo srednje stališče, 50 odstotkov jih meni, da je priprava na upokojitev potrebna, 21 odstotkov pa, da ni. Povprečna stopnja oziroma ocena potrebnosti priprave na upokojitev je 2,4.

- Večina anketirancev meni, da bi morala priprava na upokojitev potekati individualno, 44 odstotkov, ali individualno s partnerjem, 29 odstotkov. Le 20 odstotkov anketirancev je mnenja, da bi morala priprava na upokojitev potekati skupinsko.

- Anketiranci so se različno opredelili tudi glede tematike, vsebinskih sklopov, ki naj bi jih zajemala priprava na upokojitev. Večina, 76 odstotkov, meni, da je poglavitna tema, ki bi jo bilo treba obravnavati, prosti 


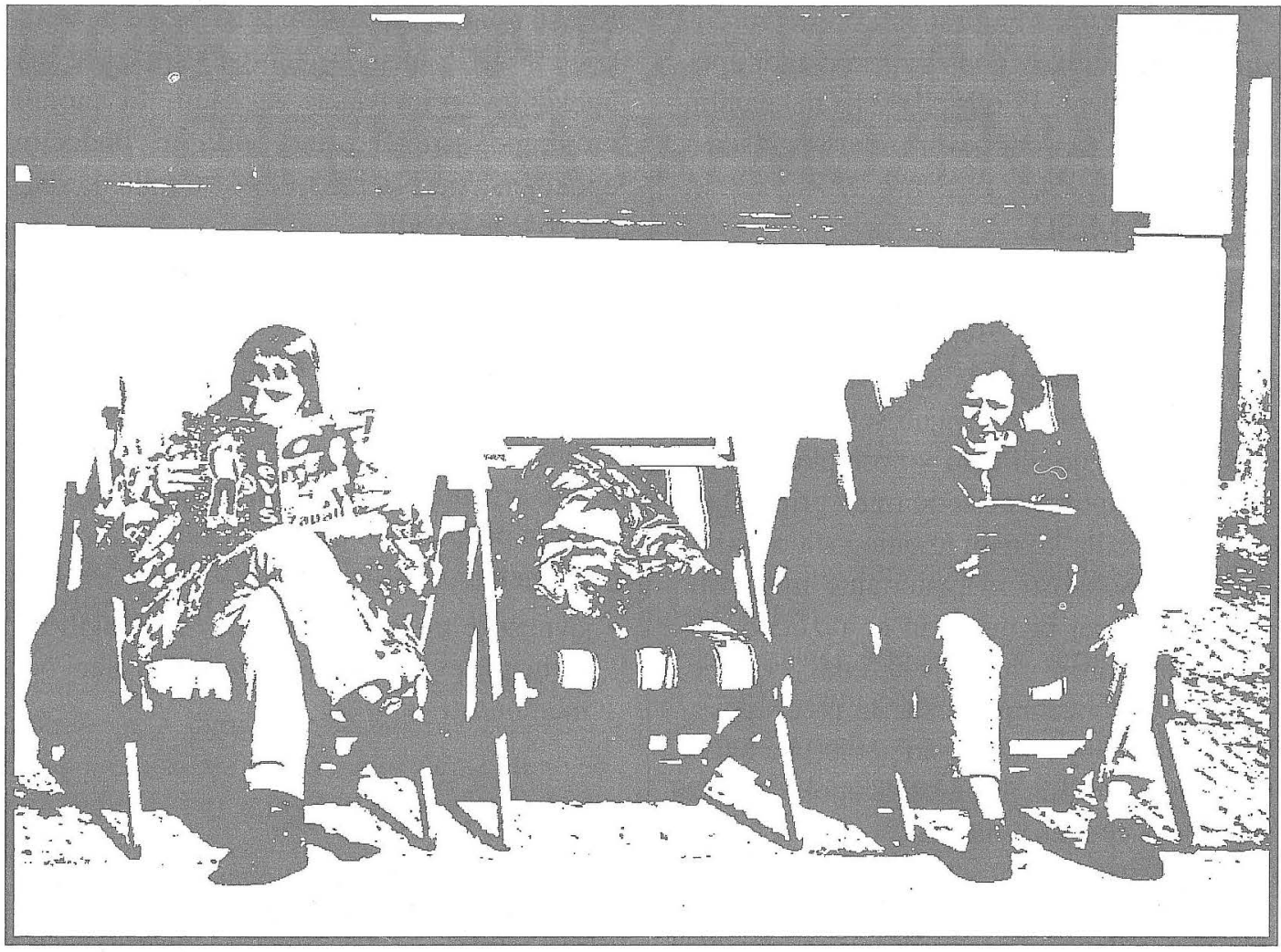

čas. S 66 odstotki sledi zdravje, 49 odstotkov jih meni, da bi bilo treba obravnavati tudi družinsko življenje, 40 odstotkov socialno in zdravstveno zavarovanje in 22 odstotkov davčna ter pravna vprašanja. Najmanj potrebe čutijo po finančnem svetovanju, zanj se je odločilo le 22 odstotkov anketirancev.

- Večini, 53 odstotkom, se je gmotno stanje spremenilo na slabše, 38 odstotkov anketirancev pa meni, da se jim ni spremenilo oziroma da je ostalo enako.

- Največ upokojencev, 67 odstotkov, se v prostem času ukvarja z vrtičkarstvom, 61 odstotkov jih gleda televizijo, 57 odstotkov jih hodi na potovanja in izlete, 53 odstotkov upokojencev v prostem času bere knjige ali pa ga preživljajo s svojo družino, 39 odstotkov upokojencev se ukvarja tudi s športom, 38 odstotkov pa najraje preživi prosti čas $\mathrm{v}$ družbi prijateljev in znancev, 13 odstotkov jih poje v pevskem zboru. Poleg tega upokojenci v prostem času rešujejo križanke (5 odstotkov), se učijo tuje jezike oziroma se izobražujejo (4 odstotki), 5 odstotkov anketirancev pa ima tudi honorarno zaposlitev. Navedli so še pomoč starejšim osebam, domačo obrt, ročna dela, kmetovanje in preživljanje prostega časa v vikendu.

- 31 odstotkov upokojencev meni, da lahko v podjetju ali drugi organizaciji, v kateri so bili zaposleni, prilagodijo delovno mesto njihovim zmogljivostim. V 16 odstotkih podjetij in drugih organizacijah tudi ne izključujejo možnosti napredovanja.

- Skrb, ki jo podjetja ali druge organizacije namenjajo upokojencem, pa se največkrat kaže $\mathrm{v}$ organiziranju upokojenskih srečanj (38 odstotkov), v podobnih ugodnostih, kot jih imajo zaposleni (37 odstotkov). 36 odstotkov podjetij svojim nekdanjim zaposle- 
nim ob praznikih in jubilejih pošlje voščilnico, 21 odstotkov podjetij prireja tudi upokojenske izlete, 19 odstotkov pa nekdanjim zaposlenim na dom pošilja interno glasilo.

\section{SKLEPNE MISLI}

Eden od načinov, ki bi lahko pripomogli k izboljšanju kakovosti življenja v starosti, so programi priprave na upokojitev. Nesmiselno pa je, če jih začnemo izvajati šele zadnje leto pred upokojitvijo ali celo v postopku upokojevanja. Na upokojitev se je treba pripravljati že v zrelih letih, ko nam to omogočajo psihofizične sposobnosti in materialne možnosti. Posameznik naj bi mislil in se različno pripravljal na starost vse svoje aktivno življenje,

\section{Priprave na upokojitev naj bi začele intenzivno potekati pet let pred upokojitvijo.} zadnjih nekaj let pred upokojitvijo (tri do pet let) pa naj bi bila priprava na upokojitev intenzivnejša.

Glede na predpostavko, da programe za upokojitev organizirajo podjetja ali druge institucije, menim, da bi morali programi priprave na upokojitev zajemati problematiko, ki določeno populacijo, vključeno $v$ program, tudi zanima. Zato bi bilo koristno pred izdelavo vsebinske zasnove priprave na upokojitev za vsako populacijo ugotoviti, kakšne so njene potrebe in zanimanja. ${ }^{2}$ Prav bi bilo tudi, da bi imeli vključeni v pripravo na upokojitev možnost izbire med skupinsko pripravo, individualno s partnerjem in individualno pripravo oziroma možnost kombiniranja različnih načinov. To na primer pomeni, da ima posameznik, če se odloči za skupinski način priprave na upokojitev, na voljo tudi individualno svetovanje.

Da bi se izognili temu, da bi priprava na upokojitev potekala samo v podjetjih in organizacijah $\mathrm{z}$ večjim številom zaposlenih, ker v njih menijo, da je potrebnejša, bi se morala majhna podjetja povezati in organizirati pripravo na upokojitev skupaj.
Ker se ponavadi programov priprave na upokojitev udeležujejo večinoma tisti, ki se na upokojitev pripravljajo že sami, bi morali programe približati tudi drugim bodočim upokojencem. Načini so lahko različni, vendar so teže izvedljivi.

$\mathrm{V}$ zvezi s pripravo na upokojitev je treba upoštevati predvsem to:

- če ni organizirana na ravni podjetja ali druge organizacije, mora biti prav tako brezplačna;

- če je organizirana na ravni podjetja, naj program poteka med delovnim časom ali takoj po njem;

- javnost je treba prek medijev in drugih informatorjev poučiti in prepričati o njeni pomembnosti.

\section{LITERATURA IN VIRI}

Gospodarski vestnik (1997/29). Največja slovenska podjetja. Gospodarski vestnik, Ljubljana.

Hojnik Zupanc, I. (1991). Prihodnost gerontoloških dejavnosti v Sloveniji, priprava na starost in upokojitev. Gerontološko društvo Slovenije, Ljubljana.

Ledbetter Hancock, B. (1990) Social work with older people. Prentice Hall, New Jersey.

International Labour Conference (1979). Older Workers: work and retirement. International Labour Office, Ženeva.

McCluskey, N., Borgata, E. (1981). Ageing and retirement, Prospects, Planning and Policy. Sage Publications, Beverly Hills.

Retirement without tears. (1979). Minister of Supply and Services Canada, Kanada.

Ušeničnik, M. (1997). Diplomska naloga: Priprava na upokojitev. Visoka šola za socialno delo, Ljubljana.

\footnotetext{
${ }^{1} V$ nekaterih organizacijah zaradi manjšega števila zaposlenih nimajo posebej organizirane kadrovske službe. $V$ takih primerih sem anketo naslovila na osebo, ki je pristojna, da o tem odloča (na primer direktor CSD, ravnatelj $O \check{S}$...).

${ }^{2}$ Gre namreč za različne skupine upokojencev: vodilni delavci, invalidski upokojenci, obrtniki, ženske, proizvodni delavci ...
} 